\title{
Grafen Oksit Katkılı Kitosan/Hidroksipropil Metilselüloz Biyonanokompozit Film Sentezi ve Anti-Kanser İlacı 5- Fluorourasil'in Kontrollü Salımında Kullanımı
}

\author{
Mürit $\mathrm{Akal}^{1}$, Muhammed Emre Demirdere ${ }^{2}$, Derya Ünlü ${ }^{3 *}$ \\ ${ }^{\mathbf{1} B u r s a ~ T e k n i k ~ U ̈ n i v e r s i t e s i, ~ M u ̈ h e n d i s l i k ~ v e ~ D o g ̆ a ~ B i l i m l e r i ~ F a k u ̈ l t e s i, ~ K i m y a ~ M u ̈ h e n d i s l i g ̆ i ~ B o ̈ l u ̈ m u ̈, ~ B u r s a, ~ T u ̈ r k i y e,(O R C I D: ~ 0000-0002-2825-0226), ~}$ \\ muritakal@gmail.com \\ ${ }^{2}$ Bursa Teknik Üniversitesi, Mühendislik ve Doğa Bilimleri Fakültesi Kimya Mühendisliği Bölümü, Bursa, Türkiye (ORCID: 0000-0002-1983-2697), \\ emredemirdere@gmail.com \\ 3* Bursa Teknik Üniversitesi, Mühendislik ve Doğa Bilimleri Fakültesi, Kimya Mühendisliği Bölümü, Bursa, Türkiye (ORCID: 0000-0001-5240-5876), \\ derya.unlu@btu.edu.tr
}

(1st International Conference on Applied Engineering and Natural Sciences ICAENS 2021, November 1-3, 2021)

(DOI:10.31590/ejosat.1012983)

\begin{abstract}
ATIF/REFERENCE: Akal, M., Demirdere, M.E. \&Unlu, D. (2021). Grafen Oksit Katkılı Kitosan/Hidroksipropil Metilselüloz Biyonanokompozit Film Sentezi ve Anti-Kanser İlacı 5-Fluorourasil'in Kontrollü Salımında Kullanımı. Avrupa Bilim ve Teknoloji Dergisi, (28), 1121-1125.

Öz

Kontrollü ilaç salım sistemleri, kullanılan ilaç miktarını en aza indirmek, ilaç alma periyodunu uzatmak, tedavi sırasında oluşabilecek yan etkileri ortadan kaldırmak amacıyla son yıllarda oldukça ilgi görmektedir. İlaç salımının kullanılmasının temel nedeni daha etkili bir tedavi yöntemi sağlamaktır. Bu çalışmada kontrollü ilaç salımı için biyonanokompozit filmler sentezlenmiştir. Biyotemelli polimerler olarak kitosan ve hidroksipropil metil selüloz kullanılmıştır. Grafen oksit ilave edilerek katkılandırılan filmlere ilaç yüklemesi yapılarak salım performansları incelenmiştir. Model ilaç olarak antikanser ilacı 5-Fluorourasil (5-Fu) seçilmiştir. Sentezlenen filmlerin kimyasal bağ yapıları Fourier dönüşümlü kızılötesi (FTIR) ile belirlenmiştir. Polimerlerin birbiri ile uyumu, karışabilirliği, eklenen katkının dağılımı taramalı elektron mikroskobu (SEM analizi) ile görüntülenmiştir. İlaç salımında filmlerin şişme derecesi önemli olduğu için suda şişme testleri yapılmıştır. Grafen oksit miktarı arttıkça başlangıçta şişme derecesi artmış ardından düşme eğilimi göstermiştir. \%20 grafen oksit katkılı kitosan/hidroksipropil metilselüloz biyonanokompozit filmde \%321.68 şişme derecesi gözlenirken, \%30 grafen oksit katkılı kitosan/hidroksipropil metilselüloz biyonanokompozit filmde \%248.95 şişme derecesi göstermiştir. İlaç tutuklama verimi grafen oksit miktarı arttıkça çok az artış göstermiştir. En yüksek ilaç tutuklama verimi 12 saatin sonunda \%30 grafen oksit katkılı kitosan/hidroksipropil metilselüloz biyonanokompozit filmde \%69.90 olarak elde edilmiştir. Aynı özellikteki filmde ilaç salım yüzdesi de 4 günün sonunda \%9.87 olarak elde edilmiştir. İlaç salımına ortam pH'ının etkisi incelendiğinde en iyi ilaç salım ortamının pH=7.4 olduğu görülmüştür. Elde edilen sonuçlar sentezlenen filmlerin geliştirilebilir olduğunu grafen oksit miktarının arttırılarak ilaç salım yüzdesinin arttırılabileceğini göstermiştir.
\end{abstract}

Anahtar Kelimeler: Fluorourasil, Grafen Oksit, İlaç Salımı, Nanokompozit film.

\section{Synthesis of Graphene Oxide Loaded Chitosan/ Hydroxypropyl Methylcellulose Bionanocomposite Films and Usage of Controlled Release of Anti-Cancer Drug 5- Fluorouracil}

\begin{abstract}
Controlled drug release systems have attracted a lot of attention in recent years in order to minimize the amount of drug used, to extend the period of taking drugs, and to eliminate the side effects that may occur during treatment. The main aim for using drug release is to provide a more effective treatment method. In this study, bionanocomposite films were synthesized for controlled drug release. Chitosan and hydroxypropyl methyl cellulose were used as biobased polymers. The release performances of graphene oxide loaded films were investigated by drug loading on the films. The anticancer drug 5-Fluorouracil was chosen as the model drug. Chemical bond structures of the synthesized films were determined by Fourier transform infrared (FTIR). Compatibility, miscibility and distribution of the added additives were observed by scanning electron microscopy (SEM analysis). The water swelling tests were performed because of the importanece of the degree of swelling of the films in drug release. As the amount of graphene oxide increased, the degree of swelling initially increased and then tended to decrease. While a swelling degree of $321.68 \%$ was observed in the $20 \%$ graphene oxide loaded
\end{abstract}

*Sorumlu Yazar:derya.unlu@btu.edu.tr 
chitosan/hydroxypropyl methylcellulose bionanocomposite film, it was $248 \%$ in the $30 \%$ graphene oxide loaded chitosan/hydroxypropyl methylcellulose bionanocomposite film. The drug encapsulation efficiency increased slightly as the amount of graphene oxide increased. The highest drug encapsulation efficiency was obtained as $69.90 \%$ in $30 \%$ graphene oxide loaded chitosan hydroxypropyl methylcellulose bionanocomposite film at the end of the 12 hours. The percentage of drug release in the same film was obtained as $9.87 \%$ at the end of 4 days. The best drug release medium was determined as $\mathrm{pH}=7.4$. The results obtained showed that the synthesized films could be improved and the percentage of drug release could be increased by increasing the amount of graphene oxide.

\section{Keywords: Drug release, Fluorouracil, Graphene oxide, Nanocomposite film.}

\section{Giriş}

Kontrollü salım sistemi, belirlenen/istenilen bir süre zarfında istenilen bir hız ile ilacın salımını gerçekleștirmektedir. Uzunca bir süredir, vücudun bazı kısımlarına bırakılan ilacın ya da uzun zamanlı ilaç salım hızını kontrol edebilen salım sistemlerinin ortaya çıkarılması için birtakım çalışmalar yürütülmektedir. Fakat sadece son birkaç yıldaki çalışmalardan istenilen sonuç alınarak çalışmalarda ilerleme kaydedilmiştir. Oldukça kısa bir süre zarfında geliştirilmiş olan salım sistemleri tıbbın birçok alanında (kardiyoloji, oftalmoloji, endokrinoloji, immünüloji ve onkoloji) faaliyete geçmiştir.

\section{Kontrollü ilaç salımı;}

$\checkmark$ Tedavi edici seviyede ilaç miktarının sabit tutulması,

$\checkmark$ Salımın belirlenmiş bir yere yapılabilmesi sebebiyle istenmeyen sonuçların minimum düzeye çekilmesi,

$\checkmark$ Gerekli olan ilaç seviyesinin düşürülebilmesi,

$\checkmark$ Kullanılması gereken ilaçlara hastanın uyum sağlayabilecek şekilde dozaj seviyesinde değişim yapilabilmesi,

$\checkmark$ Kısa yarılanma ömrüne sahip ilaçlar için ilaç yönetiminin basitleştirilmesi

gibi avantajlara sahiptir (Yalçın, 2011). Özellikle tedavi aşamasında yan etkilere de neden olan ilaçların hedef bölgeye kontrollü salımı büyük öneme sahiptir. Bu ilaçlardan biri kanser tedavisinde kullanılan 5-Fluorourasildir.

5-Fluorourasil tümör hücrelerinin, normal hücrelere göre urasili daha fazla kullandığının belirlenmesi ile sentezlenen ve ilaç haline getirilen pirimidin bazlı bir yapıdır (Özkan, 2012).. Kolon, mide, meme ve pankreas kanserlerinin tedavisinde kullanılan yarılanma ömrü kısa olan bir ilaçtır. Yarılanma ömrü kısa olduğu için ilacın antitümör etki gösterebilmesi yüksek dozda ilaç verilmesi ile mümkündür. Ancak ilacın toksik özelliği midebağırsak zehirlenmeleri, şiddetli kemik ağrıları gibi ağır yan etkilere neden olabilmektedir (Arias vd. 2008; Azhar ve Olad, 2014; Zhang vd. 2008). Başarılı bir tedavi için yan etkilerin üstesinden gelmek oldukça önemlidir; bu da, ilacın biyopolimerik sistemlerde kontrollü salımı ile sağlanabilir.

$\mathrm{Bu}$ çalışmada da biyopolimer olarak kitosan ve hidroksipropilmetilselüloz kullanılarak filmler sentezlenmiş ve ilaç salım performansları incelenmiştir. Kitosan, kabuklu deniz canlılarının (yengeç, karides vb.) iskelet yapılarında, mantarların hücre yapısında ve kelebeklerin kanatlarında bulunan doğal polisakkaritlerdendir. Herhangi bir zehirli etkisinin bulunmamas1, alerji ve tahriş edici olmamasıyla beraber, biyobozunabilir ve biyogeçirgen olması farmosetik ve medikal sektöründe kitosanı değerli bir biyomalzeme yapmaktadır (Duman ve Şenel, 2004). Hidroksipropil metilselüloz (HPMC), kontrollü ilaç salım sistemlerinde kullanılan en önemli hidrofilik taşıyıcı malzemelerden biridir. İlaç salımında tercih edilmesinin en önemli nedeni yüksek şişme özelliği göstermesidir. Biyolojik sıvı ile temas ettiğinde, haciminin artması polimer zincirinin esnemesi ve zincirler arasındaki boşlukların artması ile sonuçlanır. Bununla birlikte yapıda bulunan ilaç sistemden salınır. Ayrıca sahip oldukları yüksek yüzey aktivitesi de ilaç yükleme özelliğini iyileştirmektedir (Pingping vd. 2018; Siepmann ve Peppas, 2012).

Grafen oksitin (GO) büyük miktarda ilacın yüklenebileceği bir taşıyıcı olduğu yapılan araştırmalarla ispatlanmış ve GO'nun potansiyel bir ilaç taşıyıcısı olduğu sonucuna varılmıștır. GO bir tür iki boyutlu monatomik karbon allotropudur. GO; epoksi grupları, hidroksil grupları ve karboksil grupları gibi çok sayıda fonksiyonel grup içerir. $\mathrm{Bu}$ fonksiyonel gruplar GO'in ilaç adsorpsiyon kabiliyetini ve polimerik hidrojellerin mekanik mukavemetini arttırır. Sulu ortamlarda mükemmel dağılabilirlik, düşük toksisite, geniş özgül yüzey alanı ve farklı adsorblayıcılarla güçlü elektrostatik etkileşimler, GO'nun ilaç salımı için gelecek vaad eden bir yapıya sahip olduğunu göstermektedir (Jafari vd. 2020; Wang vd. 2018).

Bu çalışmada da grafen oksit katkılı kitosan/hidroksipropil metilselüloz biyonanokompozit filmler sentezlenerek ilaç salım performansları incelenmiştir. Sentezlenen filmlerin kimyasal bağ yapıları ve morfolojik yapıları karakterize edilmiştir. Ardından filmlerin şişme özellikleri test edilmiş ve şişme performansları belirlenmiştir. İlaç yükleme işlemi yapılarak sonrasında salım performansları incelenmiştir. Elde edilen sonuçlar bentonit yüklü kitosan/hidroksipropil metilselüloz biyonanokompozit filmlerin 5-Fluorourasilin kontrollü salımı için iyi bir aday olduğunu göstermektedir.

\section{Materyal ve Metot}

\subsection{Malzemeler}

Anti-kanser ilac1 etken maddesi 5-Fluorourasil Abcr firmasından satın alınmıştır. Nanokompzit film hazırlama polimerlerinden kitosan Sigma Aldrich, Hidroksipropilmetilselüloz Kimetsan Kimya'dan temin edilmiştir. Kitosanı çözmek için kullanılan asetik asit Merck'ten satın alınmıştır. Filmleri çapraz bağlamada kullanılacak çapraz bağ ajanı glutaraldehit Sigma Aldrich 'den ve solvent aseton Merck'ten tedarik edilmiştir. $\mathrm{pH}=7.4$ 'teki fosfat tampon çözeltisi ise Sigma Aldrich 'den satın alınmıştır. Grafen oksit ise Hazerfen Kimya Malzeme ve Enerji Teknolojileri Sanayi Ticaret A.Ş.'ten temin edilmiştir.

\subsection{Grafen Oksit Katkılı Kitosan/Hidroksipropil Metilselüloz Biyonanokompozit Film Sentezi}

Ağırlıkça \%1 kitosan, hacimce \%1 asetik asit içeren sulu çözeltide çözünmüştür. Ağırlıkça \%1 Hidroksipropilmetilselüloz (HPMC) da bir başka kapta su içerisinde karıştırılarak bir gece çözünmeye bırakılmıştır. Ağırlıkça \%1 kitosan içeren çözeltiden belirli bir miktar behere alınarak. çözelti içerisine polimer ağırlığının belirli oranlarında grafen oksit eklenmiştir. Ardından ağırlıkça \%1 HPMC içeren çözeltiden kitosan çözeltisine 40 ${ }^{\circ} \mathrm{C}$ 'de karıştırılarak eklenmiştir. Hazırlanan çözelti temiz pürüzsüz yüzeye dökülerek $25^{\circ} \mathrm{C}$ 'de 24 saat kurutmuştur. Daha 
sonra $1 \mathrm{ml}$ glutaraldehit (GA) $1 \mathrm{ml} \mathrm{HCl}$ içeren \%85 aseton- \%15 su karışımında çapraz bağlanmıştır (Calvo vd. 2018).

\subsection{Biyonanokompozit Film Karakterizasyonu}

Sentezlenen biyonanokompozit filmlerin morfolojik özellikleri Taramalı Elektron Mikroskopi ile analiz edilmiştir. Kimyasal bağ yapıları ise FTIR ile belirlenmiştir. FTIR analizi Perkin Elmer-Spectrum Two marka cihaz ile yapılmıştır. Analiz $650-4000 \mathrm{~cm}^{-1}$ aralığında 4 tarama yapılarak gerçekleştirilmiştir. Filmlerin SEM analizleri Carl Zeiss / Gemini 300 model mikroskop ile yapılmıştır. Örnekler sıvı azot ile kırılarak hazırlanmıştır. Numuneler SEM'de incelenmeden iletkenliği sağlamak amaçlı önce karbon bant üzerine konulmuş ve altınpaladyum ile kaplanmıştır.

\section{4. Şişme Testleri}

Kuru ağırlığı bilinen film numuneleri fosfat tamponu ( $\mathrm{pH}$ 7.4) banyosunda oda sicaklığında 24 saat boyunca dengeye ulaşması için bırakılmıştır. Ardından filmler su sorpsiyon kapasitelerini belirlemek için suyun içerisine bırakılarak belirli aralıklarla ağırlıkları ölçülüp kaydedilmiştir. Filmlerin şişme dereceleri Eşitlik 1 kullanılarak hesaplanmıştır.

$\mathrm{SD}=\frac{\mathrm{W}_{\mathrm{s}}-\mathrm{W}_{\mathrm{d}}}{\mathrm{W}_{\mathrm{d}}} \times 100$

$\mathrm{W}_{\mathrm{s}}$ şişmiş filmin ağırlığını, $\mathrm{W}_{\mathrm{d}}$ kuru filmin ağırlığını, SD ise sorpsiyon derecesini göstermektedir.

\subsection{5-Fluorourasil Yükleme ve Enkapsülasyon Verimi}

Biyonanokompozit filmlere ilaç yükleme işlemi şişme yöntemi ile gerçekleştirilmiştir. Belirli ağırlıktaki filmler oda sıcaklığında 24 saat boyunca belirli hacimdeki 5-Fluorourasil içeren ilaç çözeltisinde (X mg 5-Fluorourasil, hacimce \%20 aseton ve \%30 distile su) şişmeye bırakılmıştır. 5-Fluorourasilin enkapsülasyon verimliliği spektrofotometrik yöntem kullanılarak belirlenmiştir. İlaç yüklü filmler, fosfat tampon çözeltisine yerleştirilmiş ve ilacı filmlerden özütlemek için 4 gün süreyle kuvvetli bir şekilde karıştırılmıştır. 4 günün sonunda salımın gerçekleştiği çözelti alınarak $266 \mathrm{~nm}$ absorbans değerinde UV spektrofotometre kullanılarak analiz edilmiştir (Reddy vd. 2016). İlaç yükleme (enkapsülasyon verimliliğinin) sonuçları Eşitlik 2 kullanılarak hesaplanacaktır.

$$
\text { Enkapsülas yon verimi }(\%)=\frac{\% \text { Gerçek yükleme }}{\% \text { Teorik yüikleme }} \times 100
$$

salınan 5-Fu miktarı ile ilişkilendirilmiştir. Böylece filmlerin ilaç salım performansları belirlenmiştir (Reddy vd. 2016).

\subsection{5-Fluorourasil Salımı}

5-Fluorourasil yüklü biyonanokompozit filmlerden 5Fluorourasilin kontrollü salım çalışmalarında bilinen ağırlıklarda filmler $7.4 \mathrm{pH}$ değerindeki fosfat tampon çözeltisine bırakılarak ilaç salım performansları incelenmiştir. Belirli zaman aralıklarında fosfat tampon çözeltisinden numune alınıp 266 nm'de UV ile analiz edilerek absorbans değerleri kaydedilmiştir. Kaydedilen absorbans değerleri kalibrasyon grafiği kullanılarak salınan 5-Fu miktarı ile ilişkilendirilmiştir. Böylece filmlerin ilaç salım performansları belirlenmiştir (Reddy vd. 2016).

\section{Araştırma Sonuçları ve Tartışma}

\subsection{Biyonanokompozit Filmlerin Karakterizasyon Sonuçları}

Saf kitosan/hidroksipropilmetilselüloz film ve grafen oksit katkılı kitosan/hidroksipropil metilselüloz biyonanokompozit filmlerin FTIR spektrası Şekil 1'de gösterilmektedir.

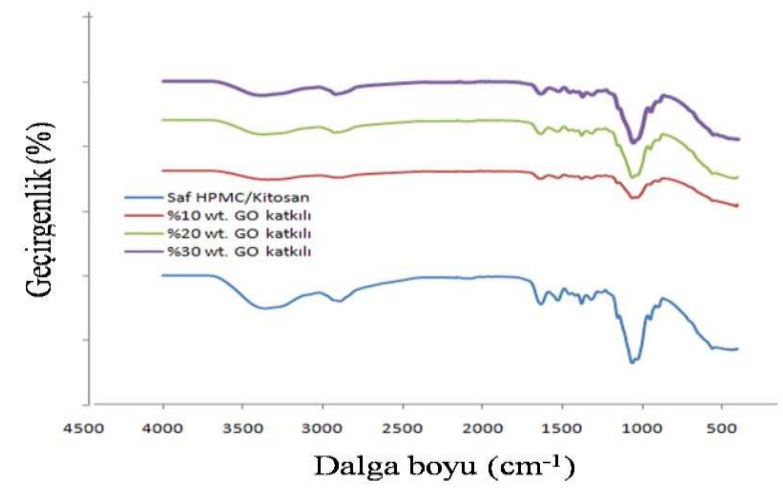

Şekil 1. Grafen Oksit Katkılı Filmlerin FT-IR Grafiği

$3450 \mathrm{~cm}^{-1}$ deki güçlü absorpsiyon band, yüzey hidroksil gruplarına ve adsorbe edilmiş suya ait $\mathrm{O}-\mathrm{H}$ gerilme titreşimlerinden kaynaklanmaktadır. $1630 \mathrm{~cm}^{-1}$ 'de $-\mathrm{C}=\mathrm{C}-$ bağları görülmektedir. $1000-1700 \mathrm{~cm}^{-1}$ aralığındaki GO'in çoklu pikleri, oksijen içeren fonksiyonel gruplara karşılık gelmektedir. 1630 $\mathrm{cm}^{-1}$ 'deki pik, karboksil ve karbonil bölgelerindeki $\mathrm{C}=\mathrm{O}$ 'nun titreşimi ile ilgilidir. $1500 \mathrm{~cm}^{-1}$ 'deki pik kitosandaki amin gruplarının N-H titreşimlerine karşılık gelir. $1050 \mathrm{~cm}^{-1}$ deki pik C-O-C- bağlarının varlığını işaret eder. $1400 \mathrm{~cm}^{-1}$ ve 1200 $\mathrm{cm}^{-1}$ 'deki bant $-\mathrm{C}-\mathrm{OH}$ grubuna karşıllı gelir (Veerapur vd. 2007).

Ancak kompozit membran üzerine GO ilavesinin düşük ekleme oranlarında katkısız film ile neredeyse aynı olduğu söylenebilir. $\mathrm{Bu}$ durumun örneğine literatürde de rastlanmıştır (Lin vd. 2017).

Şekil 2'de grafen oksit katkılı filmlerin kesit ve yüzey SEM görüntüsü görülmektedir.

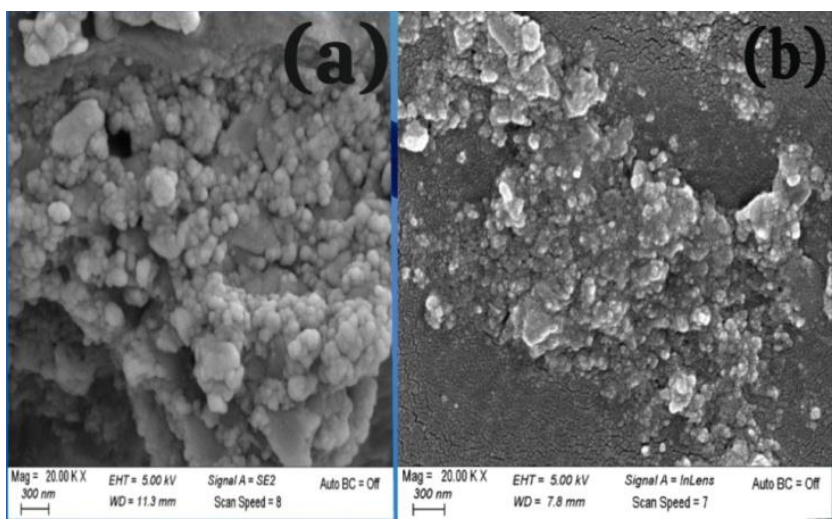

Şekil 2. (a) Grafen oksit katklll filmlerin kesit SEM görüntüsü, (b) yüzey SEM görüntüsü

Grafen oksitin polimer matrisi içerisinde oldukça yoğun bir şekilde dağıldığı, ancak yüzey görüntüsüne bakıldığında bazı noktalarda topaklaşmalar sergilediği görülmektedir. 


\subsection{Grafen Oksit Katkılı Filmlerin Şişme Davranışları}

Şişme davranışları incelenen filmlerin şişme yüzdeleri Şekil 3'te görülmektedir. Şişme deneyleri oda sıcaklığında gerçekleştirilmiştir.

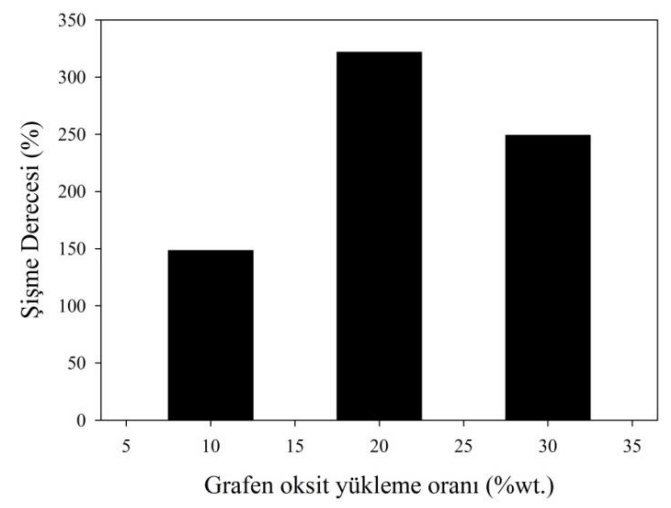

\section{Şekil 3. Grafen Oksit Miktarının Şişme Derecesine Etkisi}

GO'nun hidrofobik bölgesi ve partiküllerinin boyutu nedeniyle, grafen oksit katkılı biyonanokompozit filmlerde grafen oksit miktarı arttıkça şişme derecesinde bir azalma gerçekleşir.

GO yapısı dört farklı fonksiyonel grup içerir: karbonil, karboksilik, hidroksil ve epoksi grupları. GO yüzeyi, bu oksijen içeren fonksiyonel gruplar nedeniyle negatif yük ile yüklenmiştir. Doğrudan su ile şişme testi yapıldığında da filmlerin yüzeyindeki grafen oksit kaynaklı negatif yükler su moleküllerinin itilmesini sağladığından dolayı ağırlıkça \%30 GO eklendiğine filmin şişme derecesi azalmıştır. Şişmedeki azalma aynı zamanda filmin difüzyon kanallarını dolduran ve serbest suyun yerini alan grafen parçacıkları ile de ilgilidir, bu da rehidrasyon sürecini daha zor hale getirir. Grafen oksitin filmde polimer matrisi doldurduğu SEM görüntüleri ile de desteklenmektedir (Arruda vd. 2020).

\subsection{Grafen Oksit Katkılı Filmlerin İlaç Yükleme Çalışmaları}

Şekil 4'te görülen ilaç yüklemesi yapılmış grafen oksit katkılı filmlerin ilaç yükleme oranlarına bakarak aralarında çok küçük farklar olsa da filmlerdeki grafen oksit miktarıyla ilaç tutuklama verimi arasında doğru orantılı bir ilişki mevcuttur.

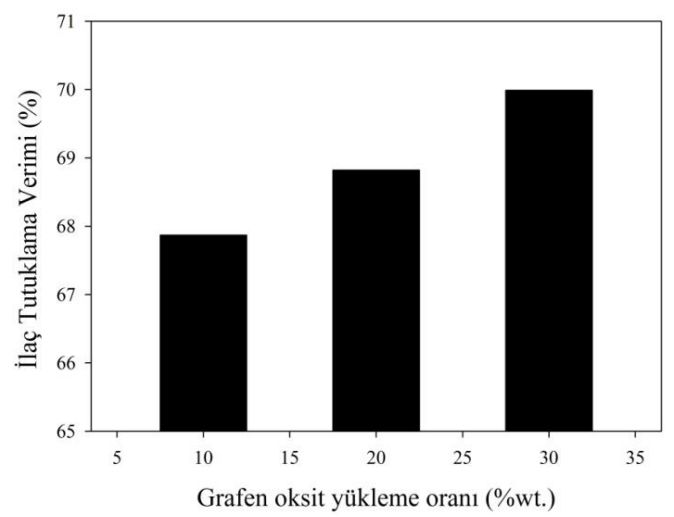

Şekil 4. Grafen Oksit Miktarının İlaç Tutuklama Verimine Etkisi

5-FU ve film içerisindeki hem GO'ten hem de kitosan ve HPMC'den kaynaklı hidrojen bağı, 5-FU'nun tutuklanma veriminde önemli rol oynar (Wang vd. 2013). Ayrica, 5-FU'nun yüzey aktivitesi ve çözelti işlenebilirliğinden dolayı, GO ile kovalent ve kovalent olmayan bağlar oluşturmaya çok uygun hidroksiller, epoksiler, karboniller ve karboksilik asit grupları gibi birçok oksijen içeren fonksiyonel grupları içerir (Wang vd. 2014).

\subsection{Grafen Oksit Katkılı Filmlerin İlaç Salım Çalışmaları}

İlaç yüklenen filmler $20 \mathrm{~mL}$ fosfat tampon çözeltisine bırakılarak 4 gün boyunca çalkalayıcıda karıştıktan sonra ilaç salımına bırakılmış ve 4. günün sonunda Şekil 5 'te ilaç salım yüzdeleri sunulan filmler çözeltiden çıkarılıp fosfat tampon çözeltisine saldığı ilaç miktarı yine çözeltilerin UV ile absorbansı ölçülerek belirlenmiştir.

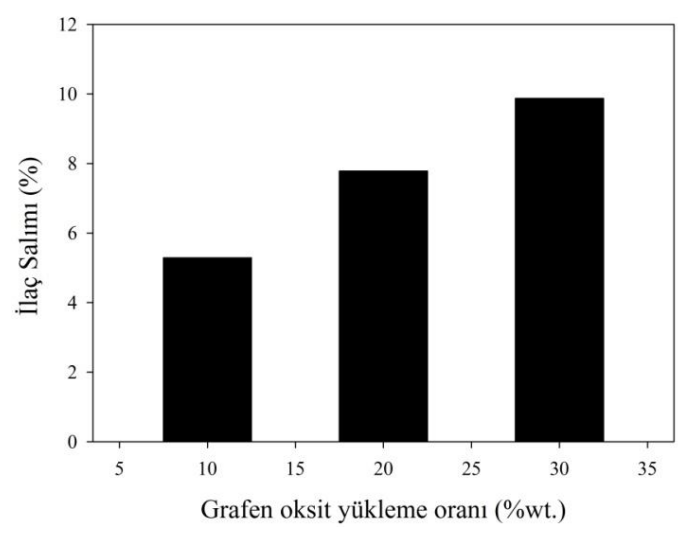

Şekil 5. Grafen Oksit Miktarının İlaç Salımına Etkisi

Grafen katkılı filmler yapıdaki grafenden dolayı, hidrojen bağı, hidrofobik ve elektrostatik etkileşimler ve bunun yanı sıra ile kovalent olmayan bağlanma karakteristiklerinden dolayı kontrollü ilaç salım sistemleri için önemli bir alternatiftir. Grafen yüzeyinin lipofilik (yağ sever) yapısı, 5-Fu'nun yüklenmesinde iyi bir etkileşim oluşmasını sağlamaktadır. Grafen katkılı filmlerin ilaç salım yüzdesi bentonit katkılı filmlere kıyasla düşüktür. Bunun sebebi, grafenin yüksek yüzey alanı ve hidrofobik etki gösteren 5-Fu'nun, güçlü $\pi-\pi$ istifleme etkileşimi yoluyla grafen katk1lı filmlere etkili bir şekilde yüklenmesi olarak düşünülmektedir. Ancak daha uzun sürelerde salımı incelendiğinde polimer matrisi oluşturan kitosan ve HPMC'nin şişmesi, polimerin difüzyon kanallarını genişlettiğinden dolayı 4 günün sonunda ilaç salımı artış göstermiştir.

\subsection{1. pH'ın İlaç Salımına Etkisi}

pH ilaç salımına önemli derecede etki etmektedir. Şekil 6'da pH'ın ilaç salım yüzdesine etkisi görülmektedir.

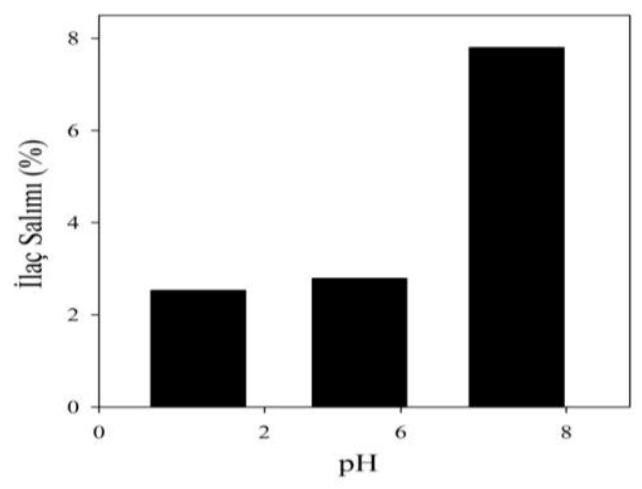

Şekil 6. pH Etkisinin İlaç Salımına Etkisi 
Grafen oksit yüklü filmlerde pH arttıkça ilaç salımının arttığı gözlenmiştir. Grafen oksit yüklü filmlerin $\mathrm{pH}=7.4$ 'te 4 günün sonunda \%7.8 düşük ilaç salım yüzdesi sergilediği görülmüştür. $\mathrm{Bu}$ durum grafen oksitin yapısında bulunan 5-Fu ile kovalent ve kovalent olmayan bağlar oluşturmaya çok uygun hidroksiller, epoksiler, karboniller ve karboksilik asitler gibi birçok oksijen içeren fonksiyonel grupların varlığı ile açıklanabilir. Grafen oksitin iyi bir ilaç bağlayıcı özellik göstermesi, 5-Fu'in salımını azaltmıştır (Wang vd. 2014).

\section{Sonuç}

Çözeltiden döküm ve solvent buharlaştırma tekniği ile grafen oksit katkılı kitosan/hidroksipropilmetilselüloz biyonanokompozit filmler hazırlanarak anti kanser ilac1 5Fluorourasilin salım performansı incelenmiştir. Hazırlanan filmlerin karakterizasyon testleri sonucunda grafen oksitin kitosan/hidroksipropilmetilselüloz filmlere başarılı bir şekilde eklendiği sonucuna ulaşılmıştır. Grafen oksit katkılı kitosan/hidroksipropilmetilselüloz filmlerin ilaç tutuklama verimliliği, film içindeki grafen oksit miktarı arttıkça artış göstermiştir. Benzer şekilde salım yüzdesi de grafen oksit içeriği arttıkça artmıştır. Dört günün sonunda $\% 30$ grafen oksit yüklü film, $\% 10$ ilaç salım performansı göstermiştir. $\mathrm{pH}$ etkisi incelendiğinde de en iyi ilaç salım ortamının $\mathrm{pH}=7.4$ olduğu görülmüştür. Elde edilen sonuçlar kontrollü salım için grafen oksit katkılı kitosan/hidroksipropilmetilselüloz biyonanokompozit filmlerin kullanılabileceğini göstermiştir. 5Fluorourasil gibi biyolojik yarılanma ömrü oldukça kısa ve salımı çok hızlı olan ilaçlar için geliştirilen biyonanokompozit film önemli bir alternatif olarak değerlendirilebilecektir.

\section{Teşekkür}

Bu çalışma, TÜBİTAK tarafından 2209-A projesi kapsamında maddi olarak desteklenmiştir.

\section{Kaynakça}

Arias, J.L., Ruiz, M.A., López-Viota, M., Delgado, A.V. (2008). Poly(alkylcyanoa- crylate) colloidal particles as vehicles forantitum our drug delivery:a comparative study. Colloids and Surfaces B: Biointerfaces, 62, 64-70.

Arruda, M. N., Souza, C. B., Eugênio, K. F. R., De, M. S., Gonçalves, E. S. (2020). Influence of swelling level on charge transmission of chitosan and reduced graphene oxide film electrodes. Materials Chemistry and Physics, 255, 123623.

Azhar, F.F., A. Olad, (2014). A study on sustained release formulations for oral delivery of 5-fluorouracil based on alginate-chitosan/montmorillonite nanocomposite systems. Applied Clay Science, 101, 288-296.

Calvo, N. L., Svetaz, L. A., Alvarez, V.A., Quiroga, A. D., Lamas, M. C., Leonardi, D. (2018). Chitosan-hydroxypropyl methylcellulose tioconazole films: A promising alternative dosage form for the treatment of vaginal candidiasis. International Journal of Pharmaceutics, 556, 181-191.

Duman, S.S., Şenel, S. (2004). Kitosan ve veteriner alandaki uygulamalar1, Veteriner Cerrahi Dergisi, 10, 62-72.

Jafari, Z., Rad, A.S., Baharfar, R., Asghari, S., Esfahani, M.R. (2020). Synthesis and application of chitosan/tripolyphosphate/graphene oxidehydrogel as a new drug delivery system for Sumatriptan Succinate. Journal of Molecular Liquids, 315, 113835.

Lin, Y.K., Nguyen, V.H., Yu, J. C.C., Lee, C.W., Deng, Y.H., Wu, J. C. S., Chen, C.L. (2017). Biodiesel production by pervaporation-assisted esterification and pre-esterification using graphene oxide/chitosan composite membranes. Journal of the Taiwan Institute of Chemical Engineers, 79, 23-30.

Özkan, M.Ç. (2012). Topikal 5-Fluorourasil Uygulamasının Epinörektomi Yapılan Sıçan Siyatik Sinir Çevresinde Skar Dokusu Oluşumu Üzerine Etkisinin Araştırılması, Uzmanlık Tezi, Uludağ Üniversitesi, Bursa, Türkiye.

Pingping, S., Yuying, W., Xueming, Z., Zhongya, Y., Meng, W., Feng, X. (2018). Preparation of Covalently Crosslinked Sodium Alginate/Hydroxypropyl Methylcellulose $\mathrm{pH}$ Sensitive Microspheres for Controlled Drug Release. BioResources, 13, 8614-8628.

Siepmann, J., Peppas, N.A. (2012). Modeling of drug release from delivery systems based on hydroxypropyl methylcellulose (HPMC). Advanced Drug Delivery Reviews, 64, 163-174.

Reddy, A., Babul, M.B., Jayaramudu, T., Sadiku, E. R., Anand, B.P., Periyar, S.S. (2016). 5-Fluorouracil Loaded ChitosanPVA/Na+MMT Nanocomposite Films for Drug Release and Antimicrobial Activity. Nano-Micro Letters, 8, 260-269.

Veerapur, R. S., Gudasi, K. B., Aminabhavi, T. M. (2007). Pervaporation dehydration of isopropanol using blend membranes of chitosan and hydroxypropyl cellulose. Journal of Membrane Science, 304, 102-111.

Wang, C., Zhang, Z., Chen, B., Gu, L., Li, Y., Yu, S. (2018). Design and evaluation of galactosylated chitosan/graphene oxide nanoparticles as a drug delivery system. Journal of Colloid and Interface Science. 516, 332-341.

Wang, J., Liu, C., Shuai, Y., Cui, X., Nie, L. (2014). Controlled release of anticancer drug using graphene oxide as a drugbinding effector in konjac glucomannan/sodium alginate hydrogels. Colloids and Surfaces B: Biointerfaces, 113, 223-229.

Wang, G., Chen, G., Wei, Z., Dong, X., Qi, M. (2013). Multifunctional $\mathrm{Fe} 3 \mathrm{O} 4 /$ graphene oxide nanocomposites for magnetic resonance imaging and drug delivery, Materials Chemistry and Physics, 141, 997-1004.

Yalçın, A. (2011). Manyetik alana duyarlı jelatin - hidrojellerin hazırlanması ve ilaç salımı profilinin incelenmesi, Yüksek Lisans Tezi, İstanbul Üniversitesi, İstanbul, Türkiye.

Zhang, N., Yin, Y., Xu, S.J., Chen, W.S. (2008). 5Fluorouracil:mechanisms of resistance and reversal strategies. Molecules, 13, 1551-1569. 